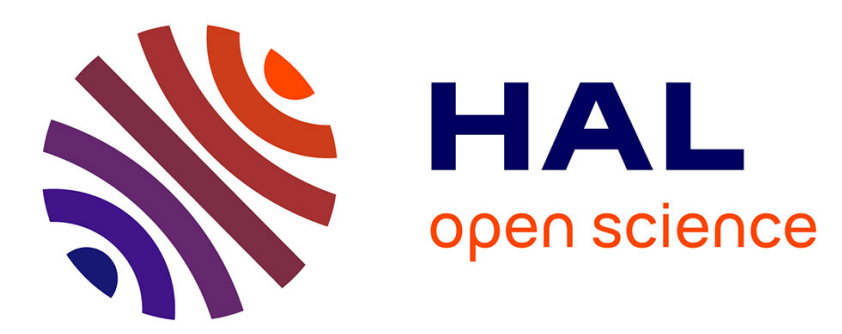

\title{
Influence of laser vibrational excitations of ethylene molecules in laser-assisted combustion diamond synthesis
}

Lisha Fan, Yunshen Zhou, Yang Gao, L. Liu, Jean-François Silvain, Yongfeng $\mathrm{Lu}$

\section{- To cite this version:}

Lisha Fan, Yunshen Zhou, Yang Gao, L. Liu, Jean-François Silvain, et al.. Influence of laser vibrational excitations of ethylene molecules in laser-assisted combustion diamond synthesis. MRS Online Proceedings Library, 2015, 1734, 10.1557/opl.2015.6 . hal-03136234

\section{HAL Id: hal-03136234 \\ https://hal.science/hal-03136234}

Submitted on 9 Feb 2021

HAL is a multi-disciplinary open access archive for the deposit and dissemination of scientific research documents, whether they are published or not. The documents may come from teaching and research institutions in France or abroad, or from public or private research centers.
L'archive ouverte pluridisciplinaire HAL, est destinée au dépôt et à la diffusion de documents scientifiques de niveau recherche, publiés ou non, émanant des établissements d'enseignement et de recherche français ou étrangers, des laboratoires publics ou privés. 


\title{
Influence of Laser Vibrational Excitations of Ethylene Molecules in Laser-Assisted Combustion Diamond Synthesis
}

\author{
L.S. Fan ${ }^{1}$, Y.S. Zhou ${ }^{1}$, M.X. Wang ${ }^{1}$, Y. Gao ${ }^{1}$, L. Liu ${ }^{1}$, J.F. Silvain ${ }^{1,2}$ and Y.F. Lu ${ }^{1}$
}

${ }^{1}$ Department of Electrical and Computer Engineering, University of Nebraska-Lincoln, Lincoln, Nebraska, 68588-0511, U.S.A.

${ }^{2}$ Institu de Chimie de la Matière Condensée de Bordeaux - ICMCB-CNRS 87, Avenue du Docteur Albert Schweitzer F-33608 Pessac Cedex - France.

\section{ABSTRACT}

Laser-induced vibrational excitation of ethylene molecules was integrated to the CVD diamond deposition process for an in-depth understanding of the energy coupling path in chemical reactions and an alternative method to enhance the diamond deposition. On- and offresonance excitations of ethylene molecules were achieved via tuning the incident laser wavelengths centered at $10.532 \mu \mathrm{m}$. With the same amount of laser power absorbed, the chemical reaction is highly accelerated with on-resonance vibrational excitation whereas energy coupling with off-resonance excitations was less efficient in influencing the combustion process. The diamond deposition rate was enhanced by a factor of 5.7 accompanied with an improvement of diamond quality index with the on-resonance excitation at $10.532 \mu \mathrm{m}$. The measured flame temperature demonstrated that the resonant vibrational excitation was an efficient route for coupling energy into the reactant molecules and steering the combustion process.

\section{INTRODUCTION}

Diamond is of great interests in industrial applications and scientific research due to the best and most extreme properties. ${ }^{1}$ In conventional CVD diamond methods, reactant molecules are indiscriminately thermally activated near thermal equilibrium. ${ }^{2-5}$ Energy is first deposited to the translational modes, and then finds their way to the internal modes (rotation, vibration, and electronic excitation) in the gas system. The conventional thermal activation is an inefficient route to drive gas reactions. Chemical reactions take place when chemical bonds are broken in reactant molecules and new bonds are formed in the products. ${ }^{6}$ Resonant vibrational excitations of reactant molecules could be more efficient in energy coupling than global thermal heating. ${ }^{6-8}$ Laser-assisted CVD takes the advantage of matching the laser light wavelength to the energy difference for a specific transition in precursor molecules. In this way, reactions can be promoted with a high energy-coupling efficiency and desired yield. ${ }^{8}$ Subramaniam et al. reported successful synthesis of diamond via pumping $\mathrm{CO}$ molecules to high vibrational states using a continuous-wavelength $(\mathrm{CW}) \mathrm{CO}$ laser operating on its lower vibrational transitions. ${ }^{9}$ However, a low production rate rendered it unpractical for industrial applications.

In this study, influence of laser excitations on diamond growth was studied using a wavelength-tunable $\mathrm{CO}_{2}$ laser. The $\mathrm{CH}_{2}$-wagging mode of ethylene $\left(\mathrm{C}_{2} \mathrm{H}_{4}\right)$ molecules has a strong infrared activity and matches one $\mathrm{CO}_{2}$ laser emission line, $10.532 \mu \mathrm{m}$. As the laser wavelength was tuned around the resonant wavelength of $10.532 \mu \mathrm{m}$, on- and off-resonance excitations of the $\mathrm{C}_{2} \mathrm{H}_{4}$ molecules were achieved. The diamond surface morphology, the growth rate, and the diamond quality were studied at different laser excitation wavelengths with the same absorbed laser power. The flame temperatures with on- and off-resonance excitations were 
measured using optical emission spectroscopy (OES), revealing that the resonant vibrational excitation of the $\mathrm{CH}_{2}$-wagging mode selectively activated the ethylene molecules and channeled the vibrational energy into the reaction pathway towards the growth of diamonds.

\section{EXPERIMENT}

Figure 1 shows a schematic experimental setup of the laser-assisted combustion CVD system. A combustion flame was produced by a gas mixture of $\mathrm{C}_{2} \mathrm{H}_{4}, \mathrm{C}_{2} \mathrm{H}_{2}$, and $\mathrm{O}_{2}$ with flow rates of $0.62,0.62$ and 1.2 standard liters per minute, respectively. $\mathrm{C}_{2} \mathrm{H}_{4}$ was added into the flame due to its strong infrared activities. A wavelength-tunable $\mathrm{CW} \mathrm{CO}$ laser (PRC Inc, $9.2 \sim 10.9$ $\mu \mathrm{m})$ was used as the irradiation source. The fundamental frequency $\left(949.3 \mathrm{~cm}^{-1}\right.$, equivalent to $10.534 \mu \mathrm{m})$ of the $\mathrm{CH}_{2}$-wagging mode $\left(v_{7}\right)$ of $\mathrm{C}_{2} \mathrm{H}_{4}$ matches one emission line of $\mathrm{CO}_{2}$ laser at $10.532 \mu \mathrm{m} .{ }^{10}$ Laser irradiation of five different wavelengths centered at $10.532 \mu \mathrm{m}$, including $10.494,10.513,10.551$ and $10.571 \mu \mathrm{m}$, were selected to irradiate the $\mathrm{C}_{2} \mathrm{H}_{4} / \mathrm{C}_{2} \mathrm{H}_{2} / \mathrm{O}_{2}$ flame in a direction normal to the flame axis and parallel with the substrate. The laser beam was focused using a $\mathrm{ZnSe}$ convex lens (focal length $=254 \mathrm{~mm}$ ) to $\sim 2 \mathrm{~mm}$ in diameter to cover the inner flame. A power meter was placed in the laser path next to the combustion flame. The absorbed laser power $(\Delta W)$ is calculated by subtracting the transmitted laser power $\left(W_{o}\right)$ from the incident laser power $\left(W_{i}\right)$. The laser incident power was adjusted to keep the absorbed power to be $20 \mathrm{~W}$ for all laser wavelengths. A tungsten carbide substrate was placed on a water-cooled X-Y-Z stage. The distance between the substrate surface and the inner flame was around $0.5 \mathrm{~mm}$. The substrate temperature was $770 \sim 780{ }^{\circ} \mathrm{C}$, monitored by a noncontact pyrometer (OS3752, Omega Engineering, Inc.). The deposition time was fixed at 1 hour.

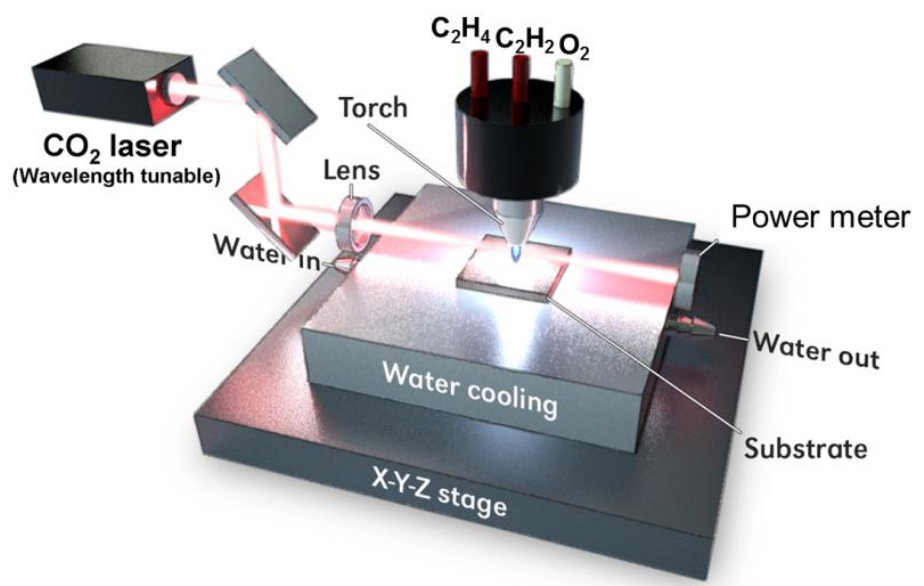

Figure 1. Schematic of the experimental setup for laser-assisted diamond growth using the $\mathrm{C}_{2} \mathrm{H}_{4} / \mathrm{C}_{2} \mathrm{H}_{2} / \mathrm{O}_{2}$ flames.

The absorption spectrum of the gaseous $\mathrm{C}_{2} \mathrm{H}_{4}$ was collected in a vacuum absorption cell at room temperature. The cell was vacuumed to a base pressure of $3.06 \times 10^{-2}$ Torr. $\mathrm{C}_{2} \mathrm{H}_{4}$ gas diluted in nitrogen was fed into the chamber at a total pressure of 100 Torr. The partial pressure of $\mathrm{C}_{2} \mathrm{H}_{4}$ was kept at 10 Torr. Surface morphologies of the diamond were characterized by a scanning electron microscope (SEM; XL-30, Philips Electronics). Diamond quality was evaluated using a micro-Raman spectrometer (inVia, Renishaw). OES of the $\mathrm{C}_{2} \mathrm{H}_{4} / \mathrm{C}_{2} \mathrm{H}_{2} / \mathrm{O}_{2}$ flames were used to measure the flame temperatures. The setup for the OES study was similar to that reported in a previous work. ${ }^{11}$ The flame images taken were proportional to the real flames in size. 


\section{DISCUSSION}

Figure 2 shows the $\mathrm{CO}_{2}$ laser energy absorption spectra of the $\mathrm{C}_{2} \mathrm{H}_{4} / \mathrm{C}_{2} \mathrm{H}_{2} / \mathrm{O}_{2}$ flame (black solid squares) and the $\mathrm{C}_{2} \mathrm{H}_{4}$ gas (blue solid triangles) at room temperature, respectively. The absorption spectra both exhibited a prominent absorption peak at $10.532 \mu \mathrm{m}$, suggesting the absorption arose from the resonant vibrational excitation of $\mathrm{C}_{2} \mathrm{H}_{4}$ molecules. The flame absorption rate increased from $3 \%$ to $15.2 \%$ when the laser wavelength was tuned from 10.476 to $10.532 \mu \mathrm{m}$ and then dropped to $3.2 \%$ as the laser wavelength was tuned to $10.591 \mu \mathrm{m}$. The absorption peak at $10.532 \mu \mathrm{m}$ (equivalent to $949.48 \mathrm{~cm}^{-1}$ ) can be attributed to the strong vibrational resonance to the $v_{7}$ fundamental $Q$ band $\left(949.3 \mathrm{~cm}^{-1}\right)$ of the $\mathrm{CH}_{2}$-wagging vibration mode of $\mathrm{C}_{2} \mathrm{H}_{4}$ molecules. ${ }^{10}$ The rotational partition functions allow the absorption of laser energy in a wide wavelength range. ${ }^{12}$ The intensity of an absorption peak, as shown in Fig. 2, decreased substantially when the laser wavelength shifted away from the central vibrational band at 949.3 $\mathrm{cm}^{-1}$ due to the decreased population in the initial state involved in the transition. To achieve the same absorption power, $20 \mathrm{~W}$, higher laser incident powers were required when the laser wavelength was tuned away from the resonant wavelength of $10.532 \mu \mathrm{m}$.

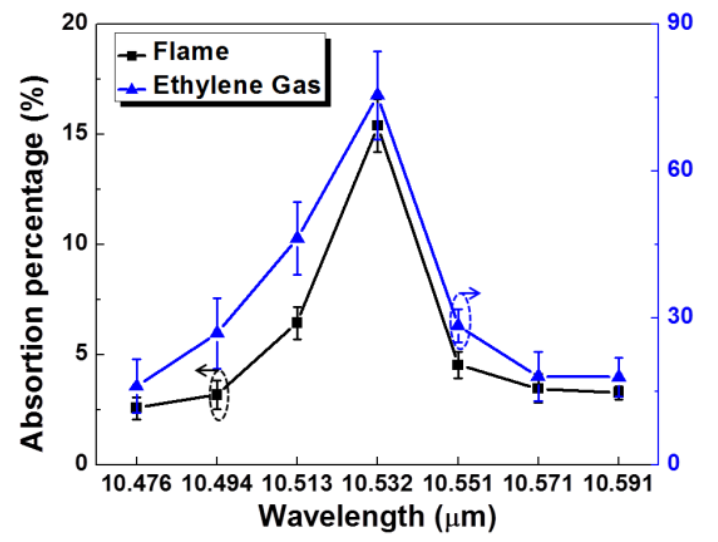

Figure 2. The absorption spectra of $\mathrm{CO}_{2}$ laser energy by $\mathrm{C}_{2} \mathrm{H}_{4} / \mathrm{C}_{2} \mathrm{H}_{2} / \mathrm{O}_{2}$ flames (black solid squares) and the $\mathrm{C}_{2} \mathrm{H}_{4}$ gas (blue solid triangles), ranging from 10.476 to $10.591 \mu \mathrm{m}$.

Morphologies and grain sizes of the diamond films deposited at different laser wavelengths are shown in Fig. 3. Diamond films deposited without laser irradiation consisted of randomly oriented grains with an average size of $2.6 \mu \mathrm{m}$ (Fig. 3(a)). With $\mathrm{CO}_{2}$ laser excitation at $10.494 \mu \mathrm{m}$, larger diamond crystals were observed in the center area of the films ( Fig. 3(b)). The diamond grain size increased as the laser wavelength approached $10.532 \mu \mathrm{m}$ and reached a maximum size of $14.3 \mu \mathrm{m}$ at $10.532 \mu \mathrm{m}$ (Fig. 3(d)). As the wavelength was further tuned to $10.571 \mu \mathrm{m}$, the diamond grain size reduced to $3.4 \mu \mathrm{m}$ (Fig. 3(e) and 3(f)). Corresponding film thickness profiles of diamond films were measured using a stylus profiler and the deposition rate was plotted as a function of laser wavelengths in Fig. 4. The diamond deposition rate without laser irradiation was $7.2 \mu \mathrm{m} / \mathrm{hr}$. The deposition rate with on-resonance excitation at $10.532 \mu \mathrm{m}$ reached $40.8 \mu \mathrm{m} / \mathrm{hr}$ and gradually decreased as the laser wavelength was tuned away from the central vibrational band. The deposition rate was enhanced by a factor of 5.7 with the resonant excitation at $10.532 \mu \mathrm{m}$ compared with the deposition rate without laser irradiation. The highly enhanced deposition rate indicates that laser resonant excitation significantly enhanced the diamond growth. 

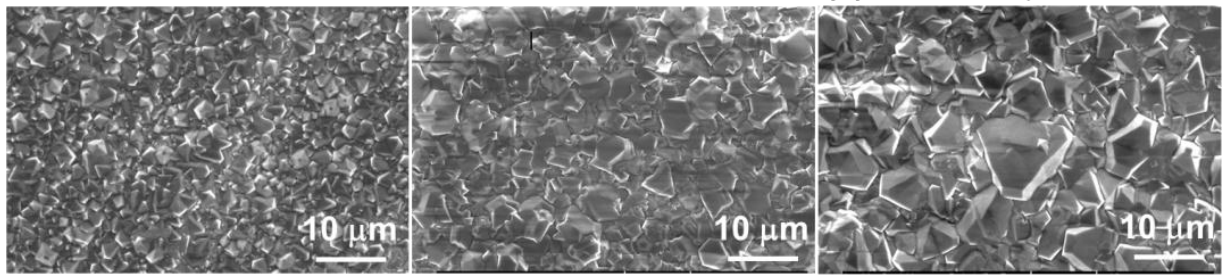

(d) $\lambda=10.532 \mu \mathrm{m}$

(e) $\lambda=10.551 \mu \mathrm{m}$

(f) $\lambda=10.571 \mu \mathrm{m}$

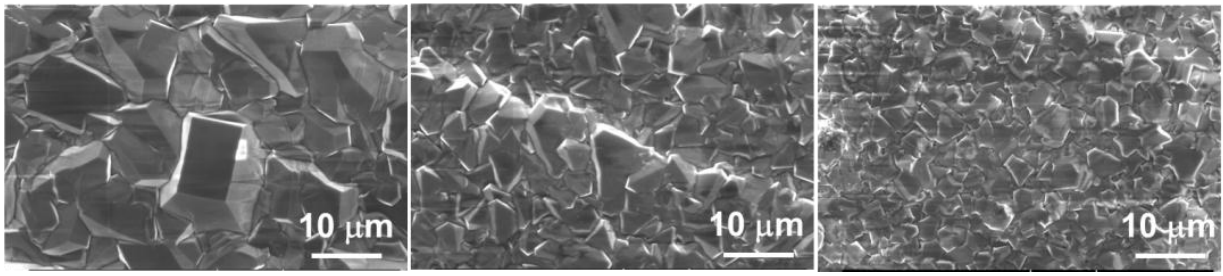

Figure 3. SEM micrographs of the center areas in the diamond films deposited using the $\mathrm{C}_{2} \mathrm{H}_{4} / \mathrm{C}_{2} \mathrm{H}_{2} / \mathrm{O}_{2}$ flames with $\mathrm{CO}_{2}$ laser excitations: (a) no laser excitation, at (b) 10.494, (c) 10.513, (d) 10.532, (e) 10.551 and 10.571 $\mu \mathrm{m}$. The absorbed laser power was $20 \mathrm{~W}$ for all laser wavelengths.

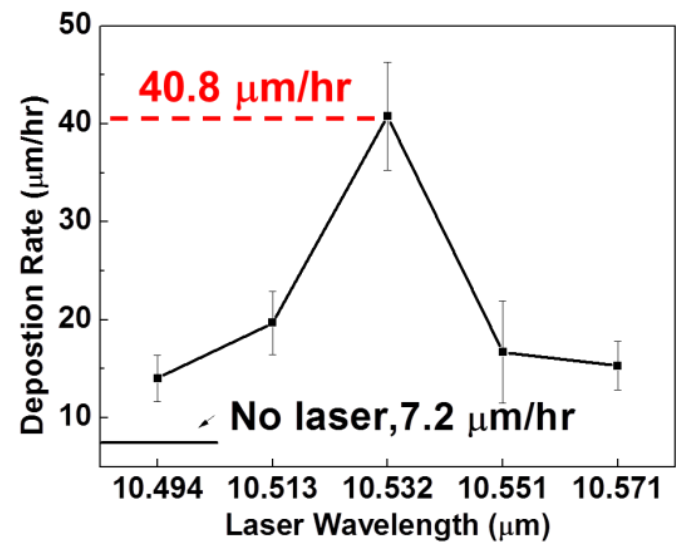

Figure 4. Deposition rates plotted as a function of laser wavelengths.

The bonding structures in the diamond films were characterized using Raman spectroscopy as shown in Fig. 5(a). A sharp peak around $1332 \mathrm{~cm}^{-1}$ associated with a weak band at $1370 \mathrm{~cm}^{-1}$ and a broad band at $1550 \mathrm{~cm}^{-1}$ were observed in all samples. The Raman peak centered at $1332 \mathrm{~cm}^{-1}$ is a typical diamond peak. The band at $1370 \mathrm{~cm}^{-1}$ (D-band) and the broadband centered at $1550 \mathrm{~cm}^{-1}$ (G-band) can be attributed to non-diamond carbon contents. ${ }^{13}$ The sample deposited without laser excitation exhibited a strong G-band and a relatively weak diamond peak. As the laser wavelength was tuned close to $10.532 \mu \mathrm{m}$, the diamond peak became much stronger whereas G-band intensity decreased. The G-band of the diamond film deposited under the laser excitation at $10.532 \mu \mathrm{m}$ was invisible, indicating a high diamond quality with a pure diamond phase. As the wavelength was further tuned from 10.551 to $10.571 \mu \mathrm{m}$, the diamond peaks broadened and weakened while G-band increased again. To analyze the diamond quality, quality factors $Q_{i}=I_{\text {diamond }} /\left(I_{\text {diamond }}+I_{\text {a-carbon }} / 233\right)$ were derived from the Raman spectra, with $I_{\text {diamond }}$ and $I_{\text {a-carbon }}$ being the integrated intensities of the diamond peak and the sum of the intensities of the observed non-diamond carbon features, respectively, shown in Fig. 5(b). ${ }^{14}$ The diamond obtained with the laser excitation at $10.532 \mu \mathrm{m}$ had the highest diamond quality factor value, $96.78 \%$, which is $6.05 \%$ higher than that without laser excitation. 
(a)

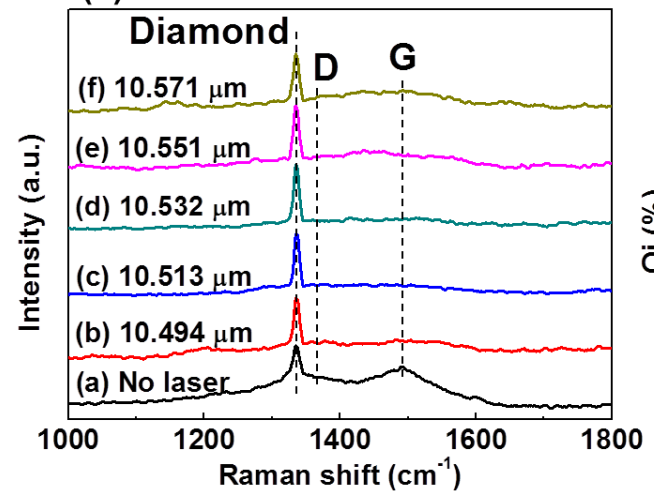

(b)

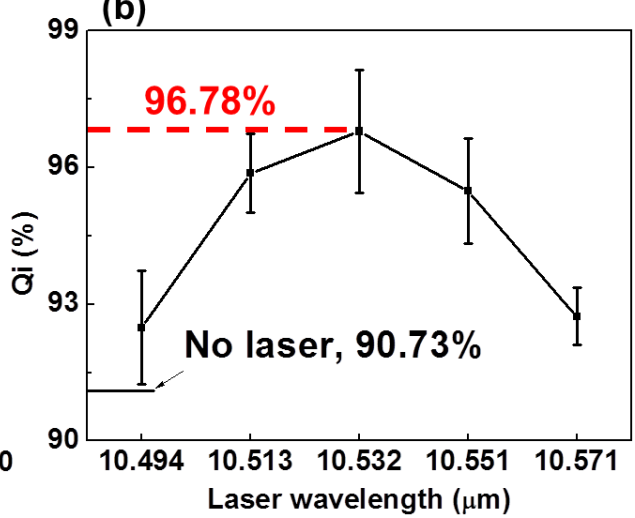

Figure 5. (a) Raman spectra of the diamond films deposited using $\mathrm{C}_{2} \mathrm{H}_{4} / \mathrm{C}_{2} \mathrm{H}_{2} / \mathrm{O}_{2}$ flames without and with $\mathrm{CO}_{2}$ laser excitations at different laser wavelengths; (b) the diamond quality index factors of the diamond films plotted as a function of laser wavelengths.

Figure 6(a) shows optical images of the $\mathrm{C}_{2} \mathrm{H}_{4} / \mathrm{C}_{2} \mathrm{H}_{2} / \mathrm{O}_{2}$ flames under laser irradiation at different laser wavelengths. The length of the inner flame was about $5 \mathrm{~mm}$ without the laser irradiation. When irradiated by the IR laser at laser wavelengths from $10.494 \mu \mathrm{m}$ to $10.532 \mu \mathrm{m}$, the inner flame shrank continuously in length and expanded in diameter. When the wavelength was tuned from 10.532 to $10.571 \mu \mathrm{m}$, the flame shape bounced back with increased inner flame length and reduced diameter. When irradiated at $10.532 \mu \mathrm{m}$, the length of the inner flame was the shortest around $3.03 \mathrm{~mm}$ with a $57 \%$ expansion in the diameter compared with the flame without laser irradiation. The brightest flame was found when the vibrational band was resonantly excited at $10.532 \mu \mathrm{m}$. As evidenced by the flame shape and brightness variations, resonant excitation of the vibrational mode was an effective approach in accelerating the combustion reaction process.

(a)

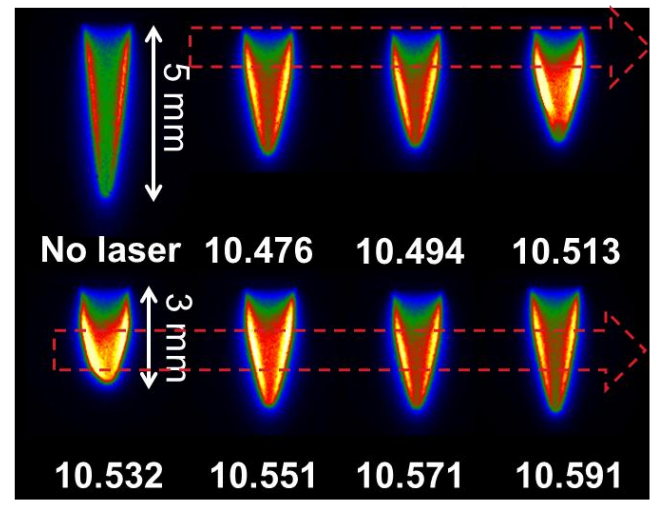

(b)

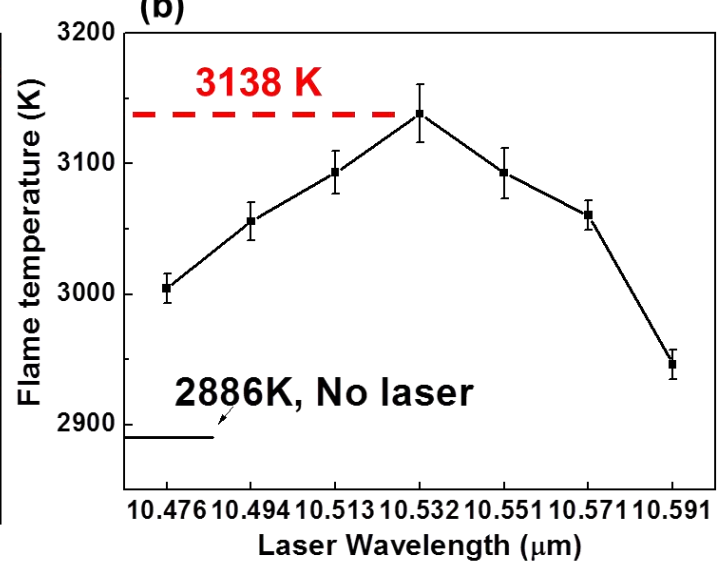

Figure 6. (a) Optical images of the $\mathrm{C}_{2} \mathrm{H}_{4} / \mathrm{C}_{2} \mathrm{H}_{2} / \mathrm{O}_{2}$ flames without and with laser excitations at different laser wavelengths. (b) The $\mathrm{C}_{2} \mathrm{H}_{4} / \mathrm{C}_{2} \mathrm{H}_{2} / \mathrm{O}_{2}$ flame temperatures plotted as a function of laser wavelengths.

The flame temperatures were measured through $\mathrm{CH}$ rotational emission band. Figure 6(b) shows the flame temperature at the inner flame middle with respect to laser wavelengths. Compared with the off-resonance excitations, the on-resonance excitation of the $\mathrm{CH}_{2}$-wagging mode led to the highest flame temperature even with the same amount of laser power absorbed by the flames. The $\mathrm{CH}$ rotational temperature increased from $2886 \mathrm{~K}$ (without laser irradiation) to $3000 \mathrm{~K}$ (laser irradiation at $10.476 \mu \mathrm{m}$ ), reached the highest point at $3138 \mathrm{~K}$ (resonant 
excitation of the $v_{7}$ vibrational band at $10.532 \mu \mathrm{m}$ ), and bounced back to $2925 \mathrm{~K}$ (laser irradiation at $10.591 \mu \mathrm{m})$.

The flame temperature profile with regard to laser wavelengths suggested that the laser irradiation modified the combustion process in a way that increased the flame temperature. The high flame temperature played an importance role in enhancing the diamond deposition. At a high temperature (> $3000 \mathrm{~K})$, a significant fraction of hydrogen molecules in the flames were converted into atomic hydrogen as expressed by the reaction: ${ }^{15}$

$$
\mathrm{H}_{2} \rightarrow \mathrm{H}+\mathrm{H}
$$

The degree of the hydrogen dissociation strongly depends on the temperature. ${ }^{15}$ The high degree of atomic hydrogen production at the high flame temperature under the on-resonance excitation led to the observed diamond quality improvement and growth rate increase.

\section{CONCLUSIONS}

The influence of on- and off-resonance excitations of ethylene molecules in combustion diamond deposition were studies. The IR-laser on-resonance excitation at the wavelength of $10.532 \mu \mathrm{m}$ was more efficient than the off-resonance excitations in exciting the $\mathrm{C}_{2} \mathrm{H}_{4}$ molecules, enhancing the deposition rate and improving diamond quality. The deposition rate was enhanced by a factor of 5.7 with on-resonance excitation at $10.532 \mu \mathrm{m}$ compared with that without laser irradiation. The flame shape and brightness variations with respect to laser wavelengths revealed a highly efficient energy coupling and significantly accelerated reactions with the on-resonance laser excitation at $10.532 \mu \mathrm{m}$. The high flame temperature with on-resonance laser excitation facilitated the atomic $\mathrm{H}$ generation, which was beneficial for the diamond deposition. It is demonstrated that the vibrational resonant excitation was more efficient in promoting chemical reactions.

\section{ACKNOWLEDGMENTS}

This research work was financially supported by National Science Foundation (CMMI 1129613 and 1068510) and Office of Naval Research (N00014-09-7581-0943)

\section{REFERENCES}

1. J.J. Gracio, Q.H. Fan and J.C. Madaleno, J. Phys. D: Appl. Phys. 43, 374017 (2010).

2. R. Haubner and B. Lux, Diamond Relat. Mater. 2, 1277 (1993).

3. T.S. McCauley and Y.K. Vohra, Appl. Phys. Lett. 66, 1486 (1995).

4. J. Asmussen, T.A. Grotjohn, T. Schuelke, M.F. Becker and M.K. Yaran, Appl. Phys. Lett. 93, 031502 (2008).

5. Y.S. Zou, Y. Yang, Y.M. Chong, Q. Ye, B. He, Z.Q. Yao, W.J. Zhang, S.T. Lee, Y. Cai, and H.S. Chu, Cryst. Growth Des. 8, 1770 (2008).

6. F.F. Crim, Science 316, 1707(2007).

7. R.N. Zare, Science 279, 1875 (1998).

8. S. Yan, Y.T. Wu, B. Zhang, X.F. Yue, and K. Liu, Science 316, 1723 (2007).

9. J.H.D. Rebello, D.L. Straub and V.V. Subramaniam, J. Appl. Phys. 72, 1133 (1992).

10. W.L. Smith and I.M. Mills, J. Chem. Phys. 40, 2095 (1964).

11. X.N. He, X.K. Shen, T. Gebre, Z.Q. Xie, L. Jiang and Y.F. Lu, Appl. Opt. 49, 1555 (2010).

12. J.L. McHale, Molecular Spectroscopy, (Pearson Education, 1999).

13. A.C. Ferrari and B. Roberson, J. Phil. Trans. R. Soc. Lond. A 362, 2477 (2004).

14. A.M. Zaitsev, Optical properties of diamond: a data handbook. (Springer, Berlin; New York, 2001).

15. J.S. Kim, and M.A. Cappelli, J Appl Phys 84, 4595 (1998). 